\title{
No es beneficioso normalizar totalmente la hemoglobina con eritropoyetina en pacientes insuficiencia renal crónica
}

Absence of benefit of complet normalizing of hemoglobin with eritropoyetin in patients with chronic kidney disease

\section{Objetivo}

Evaluar si la corrección total de la anemia con eritropoyetina (EPO) en pacientes con insuficiencia renal crónica (IRC) reduce el riesgo cardiovascular (CV).

\section{Diseño}

Ensayo abierto controlado y aleatorizado (ECCA).

\section{Lugar}

94 centros de Europa, Asia y Latinoamérica.

\section{Pacientes}

603 adultos con filtrado glomerular (FG) de 15 a 35 $\mathrm{mL} / \mathrm{min} / 1,73 \mathrm{~m} 2)$ hemoglobina $(\mathrm{Hb}) 11$ a $12,5 \mathrm{~g} / \mathrm{dL}$ y tensión arterial (TA) menor a 170/95 mmHg. Criterios de exclusión: requerimiento de diálisis en los siguientes seis meses, enfermedad CV avanzada, anemia no-renal, menos de $50 \mathrm{ng} / \mathrm{mL}$ de ferritina, PCR mayor a $15 \mathrm{mg} / \mathrm{L}$, haber recibido EPO o transfusión sanguínea en los meses previos.

\section{Intervención}

Aleatorización a recibir EPO: 1) para mantener una $\mathrm{Hb}$ entre 13 y $15 \mathrm{~g} / \mathrm{dL}$ (grupo intervención: $\mathrm{Gl}$ ); 2) para mantenerla entre 10,5 y $11,5 \mathrm{gr} / \mathrm{dL}$ (control: GC).

\section{Medición de resultados principales}

Tiempo al primer evento CV (muerte súbita, infarto de miocardio, accidente cerebrovascular e isquémico transitorio, insuficiencia cardíaca aguda, angor, arteriopatía periférica complicada) con análisis por intención de tratar, seguimiento de tres
Drüeke T y col, N Engl J Med. 2006; 355:2071-84 años y desconocimiento de la asignación terapéutica por evaluadores de los resultados.

\section{Resultados principales}

Las características basales fueron similares, pero $43 \%$ de los asignados al GI recibía ß-bloqueantes (BB) contra $34 \%$ de los del GC $(p=0,02)$ perdiéndose del seguimiento el $25 \%$ GT vs. el $17 \%$ del $\mathrm{GC}(\mathrm{p}=0,002)$. Los principales efectos se presentan en la tabla 1. La frecuencia de hipertensión arterial (HTA) $(p=0,005)$ y el inicio de diálisis $(p=0,03)$ fueron significativamente mayores en el GT.

Tabla 1: principales efectos de la corrección completa vs. parcial de la anemia.

\begin{tabular}{l|c|c|c}
\multirow{2}{*}{ Resultados } & \multicolumn{2}{|c|}{ Gorrección } & \multirow{2}{*}{ HR (IC95\%) } \\
\cline { 2 - 3 } & Completa (n=301) & Parcial(n=302) & Eventos cardiovasculares \\
\hline Muertes & 58 & 47 & $0,78(0,53-1,14)$ \\
\hline Percepción de salud (SF36) & +4 & 21 & $0,66(0,38-1,15)$ \\
\hline
\end{tabular}

\section{Conclusiones}

La completa corrección con EPO de la anemia asociada a IRC no redujo la mortalidad ni el riesgo $\mathrm{CV}$.

Palabras clave: anemia, eritropoyetina, insuficiencia renal crónica, enfermedad cardiovascular

Key Words: anaemia, erythropoietin, chronic renal insufficiency, cardiovascular diseases. Fuente de financiamiento: Hoffmann La Roche. Switzerland.

\section{Comentario}

Este ensayo y otros similares ${ }^{1-3}$ mostraron consistentemente que la corrección total de la anemia no disminuye el riesgo CV ni la mortalidad e incluso podría aumentarlo. La frecuencia de inicio de diálisis e HTA fue significativamente mayor en el Gl, mientras que percepción de la salud fue significativamente mejor en el Gl.

Como este trabajo no fue ciego y tuvo $21 \%$ de pérdidas (significativamente más altas en el GT, cuyos pacientes recibían BB en mayor proporción) esto sugiere posibles sesgos de selección ${ }^{\star} 4-6$ o de observación ${ }^{\star 4,7-9}$. Estas debilidades metodológicas, pueden exagerar el resultado de la intervención $n^{4-9}$, de tal suerte que normalizar la $\mathrm{Hb}$ con EPO puede no sólo no ser beneficioso, sino perjudicial, como han reportado otros estudios1-3. Es por ello que la Administración de Drogas y
Alimentos de EEUU recomienda no superar los $12 \mathrm{~g} / \mathrm{dL}$ de $\mathrm{HB}$ con estimulantes de la eritropoyesis ${ }^{10}$.

\section{Conclusiones del comentador}

La anemia de la IRC/diálisis es secundaria a uremia, intoxicación mineral, síndrome inflamatorio, residuos de desinfectantes, etc., sobre los que puede trabajarse buscando beneficios con plausibilidad fisiopatológica ${ }^{11-12}$. El uso de estimulantes de la eritropoyesis debería ser prudente, sólo luego de corregidos los factores causales y buscando un nivel de $\mathrm{Hb}$ entre 10 y $11,5 \mathrm{~g} / \mathrm{dL}$.

Ver glosario*

Marcelo Chaves [ Médico especialista en Nefrología. Instituto de Nefrología de Entre Ríos. ]

Chaves M. La corrección con eritropoyetina de la anemia por insuficiencia renal crónica no reduce el riesgo cardiovascular. Evid actual pract ambul 10(4);106Jul-Ago.2007. Drueke TB, Locatelli F, Clyne N, Eckardt KU, Macdougall IC, Tsakiris D, Burger HU, Scherhag A; CREATE Investigators. Normalization of hemoglobin level in patients with chronic kidney disease and anemia. N Engl J Med. 2006; 355(20):2071-84. PMID: 17108342

Referencias

1. Besarab A y col. N Engl J Med. 1998; 339 (9): 584-90

2. Parfrey PS y col. J Am Soc Nephrol 2005; 16: 2180-9

3. Singh AK y col. N Engl J Med. 2006; 355 (20): 2085-98

4. Intervention studies. In: Epidemiology in Medicine, Hennekens ChH, Buring JL, Mayrent SL editors. Little, Brown. 1987: 178-212.

5. Schulz KF y col. The Lancet 2002; 359: 515-19.

6. Schulz KF y col. The Lancet 2002; 359: 614-18.

6. Schulz KF y col. The Lancet 2002; 359: 614-18.
7. Schulz KF y col. The Lancet 2002; 359: 696-700.

7. Schulz KF y col. The Lancet 2002; 359: 696-700.
8. Sample size slippages in randomised trials: exclusions and the lost and wayward. The Lancet 2002 March 2; 359: 781-85

9. Setting up a Multivariable Analysis: Subjects. In: Multivariable Analysis, Katz MH editor. Cambridge: Cambridge University Press. $1999: 60-83$.

10. FDA Public Health Advisory. Epoietin alfa. www.fda.gov/eder/drug/advisory/RHE2007.htm. Accessed March 112007

11. Rahmati MA y col. Int J Artif Organs 2004; 27 (8): 723-7

12. Ayus JC y col. J Am Soc Nephrol 2005; 16: 2778-88 